\title{
Transumbilical laparoscopically assisted appendectomy in children
}

\author{
A. Hussain · S. El-Hasani
}

Published online: 1 January 2009

(C) Springer Science+Business Media, LLC 2008

\section{Dear Editor:}

We read with great interest the article Transumbilical Laparoscopically Assisted Appendectomy in Children published in Surgical Endoscopy [1]. The article compared the cost effectiveness between the two arms of the study, concluding that transumblical laparoscopically assisted appendectomy (TULAA) costs 7.8 times less than laparoscopic appendectomy (LA), 8.1 times less than LA using staplers, and 6.5 times less than LA using loops. The author mentioned that morbidity in form of wound infections was recorded for two patients $(4.6 \%)$ in the LA group and four patients $(13.7 \%)$ in the TULAA group $(p=0.17)$, concluding that this infection rate was not significant.

Although the study clearly shows the low cost of TULAA and concludes that the infection rate is not significant, we think the infection rate is clinically significant (4 of 29 patients, 13.7\%). Such a high rate can be associated with extra cost for antibiotics, added surgical intervention, and prolonged hospital stay [2].

The technique of delivering the appendix through the umbilicus in performing the appendectomy is associated with potential contamination of the umbilical wound and possible subsequent infections. Extra precaution should be ensured to reduce the infection if the described technique to be used.
We have published a report describing 200 patients who underwent laparoscopic appendectomy, showing that the port infection rate can be kept to a minimum of $2 \%$ by delivering the infected specimen through the port itself, thus preventing any contact with the wound [3]. Moreover in two of our four patients who experienced infection, the appendix was retrieved directly through the wound and not through the port.

If the infection rate in TULAA can be reduced, then we can provide the advantages of the minimal access technique and the low cost of the procedure.

\section{References}

1. Visnjic S (2008) Transumbilical laparoscopically assisted appendectomy in children. Surg Endosc 22:1667-1671

2. Khan MN, Fayyad T, Cecil TD, Moran BJ (2007) Laparoscopic versus open appendectomy: the risk of postoperative infectious complications. JSLS 11:363-367

3. Hussain A, Mahmood H, Singhal T, Balakrishnan S, El-Hasani S (2008) Laparoscopic appendectomy in a district hospital: does the technique influence the outcome? J Laparoendosc Adv Surg Tech A $18: 204-208$

A. Hussain $(\bowtie) \cdot$ S. El-Hasani

Minimal Access Unit, General Surgery Department,

Princess Royal University Hospital, Farnborough Common,

BR6 9XA, Orpington, Greater London, UK

e-mail: azahrahussain@yahoo.com 